\title{
Imprinting of Dull Roll Surface Texture to Carbon Steel Strips in Temper Rolling by Dry Condition
}

\author{
Naoki NAGASE, ${ }^{1)}$ Seiichi SHIDO'1) and Ikuo YARITA ${ }^{2 l}$ \\ 1) Lubricants Reseach Laboratory Idemitsu Kosan Co., Ltd., 24-4, Anesakikaigan, Ichihara-shi, Chiba $299-0107$ Japan. \\ 2) Department of Mechanical Science \& Engineering, Chiba Institute of Technology, 2-17-1, Tsudanuma, Narashino-shi, Chiba \\ 275-0016 Japan.
}

(Received on August 4, 2008; accepted on January 27, 2009; originally published in Tetsu-to-Hagané, Vol. 94, 2008, No.10, pp. 422-428)

\begin{abstract}
One of the important qualities of a cold-rolled steel sheet is the surface texture, which is obtained by imprinting a dull-roll surface texture. It is controlled by actual operation data and experiences, because the mechanism of the surface imprinting has not been clarified because of the complexity of elastic-plastic deformation of the rolled sheet in temper rolling.

In this paper, surface imprinting is investigated in temper rolling as dry rolling of a 4-high rolling mill. Temper rolling experiments for as-annealed low-carbon steel strips and as-annealed high-carbon steel strips were conducted in the range of 1 to $11 \%$ reductions. Electric-discharged dull rolls and shot-dull rolls were employed. Surface microstructures of temper rolled strips were observed directly, as well as surface textures in terms of the arithmetical mean deviation of the assessed profile (Ra), material ratio curves, and probability densities applied to compare the surface imprinting.

As a result, the electric-discharged dull roll shows better surface imprinting than the shot-dull roll. The peak part of the roll surface is more easily imprinted on the steel sheet to form the valley part when the electric-discharged dull roll is used than when the shot-dull roll is used.
\end{abstract}

KEY WORDS: temper rolling; dull roll; rolling force; surface imprinting; surface texture; dry; material ratio curve; probability density.

\section{Introduction}

The surface roughness of cold-rolled steel sheet is an important quality item because the roughness greatly affects the press formability and image clarity after the coating of the steel sheet after the temper rolling process. Surface roughness is obtained by imprinting a dull roll surface texture on a steel sheet surface. Although surface imprinting on the steel sheet surface is greatly affected by roll surface texture and rolling conditions, the mechanism of surface imprinting has not been clarified ${ }^{1-6)}$ because of the complexity of elastic-plastic deformation of the rolled sheet in temper rolling. Surface conditions of roll and steel sheet are usually evaluated only by surface roughness i.e. Ra, however it is not enough to explain the imprinting phenomenon. Therefore, surface imprinting is controlled, based on previously obtained operational data and experiences in actual temper rolling mills. In the recent paper, we proposed that the use of water-soluble lubricant decreases roll micro-wear more than under dry condition (without using any lubricants).

In this paper, the influences of roll surface texture on surface imprinting have been evaluated in temper rolling. ${ }^{7-14)}$ Temper rolling experiments for as-annealed carbon steel strips have been performed using a 4-high rolling mill under dry condition. An electric-discharged dull roll and shot dull roll were employed as the work rolls. Surface textures of the rolls were observed directly. Surface textures are evaluated in terms of the arithmetical mean deviation of the assessed profile $(\mathrm{Ra})$ and material ratio ( $\mathrm{Rmr})$.

\section{Experimental Procedure}

\subsection{Materials}

Both as-annealed high-carbon steel strips and as-annealed low-carbon steel strips were employed. The width and length of these steel strips are $50 \mathrm{~mm}$ and $250 \mathrm{~m}$ respectively. Figure 1 shows the relationship between true stress and true strain of the high-carbon and low-carbon steel strips, which were obtained by tensile tests at speeds of $100 \mathrm{~mm} / \mathrm{min}$ and $2 \mathrm{~mm} / \mathrm{min}$. At tensile speed of $100 \mathrm{~mm} / \mathrm{min}$, the upper yield point and the lower yield point of the high-carbon steel are $454 \mathrm{MPa}$ and $427 \mathrm{MPa}$ respectively. Otherwise, the upper and the lower yield point of the low-carbon steel are $328 \mathrm{MPa}$ and $320 \mathrm{MPa}$ respectively. The strain at the yield point of the high and the lowcarbon steel are $4 \%$ and $8 \%$ respectively. The Ra of both these strip surfaces is $0.2 \mu \mathrm{m}$. The hardness of the high-carbon steel is $158 \mathrm{Hv}_{(10)}$, which is equivalent to $24 \mathrm{Hs}$. The hardness of the low-carbon steel is $95 \mathrm{Hv}_{(10)}$. These strips were degreased by an alkaline agent before temper rolling. 

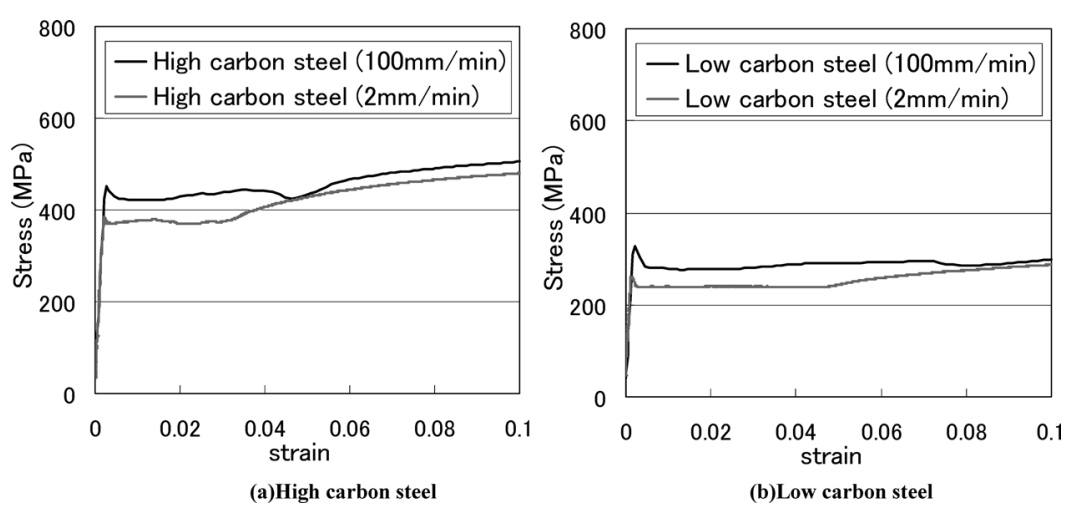

Fig. 1. True stress-true strain curves of test carbon steels.

Table 1. Rolling mill specifications and temper rolling conditions in laboratory mill.

\begin{tabular}{|c|c|c|}
\hline Mill type & & 4-high \\
\hline \multirow[t]{6}{*}{ Work roll } & Roll material & SUJ2 \\
\hline & Diameter (mm) & $131 \sim 133$ \\
\hline & \multirow[t]{2}{*}{ Hardness Hs } & Electric-discharged roll: 83 \\
\hline & & Shot dull roll: 89 \\
\hline & \multirow[t]{2}{*}{ Roughness $\operatorname{Ra}(\mu \mathrm{m})$} & Electric-discharged roll : $2.1 \sim 2.3$ \\
\hline & & Shot dull roll: $1.2 \sim 1.4$ \\
\hline \multirow[t]{4}{*}{ Back up roll } & Roll material & SUJ2 \\
\hline & Diameter $(\mathrm{mm})$ & 200 \\
\hline & Hardness Hs & 85 \\
\hline & Roughness $\operatorname{Ra}(\mu \mathrm{m})$ & 0.25 \\
\hline \multirow[t]{2}{*}{ Roll speed } & (1) Normal $(\mathrm{m} / \mathrm{min})$ & 50 \\
\hline & (2) Low $(\mathrm{m} / \mathrm{min})$ & 7.5 \\
\hline Reduction & $(\%)$ & $1 \sim 11$ \\
\hline Tension & $(\mathrm{MPa})$ & Entry32.4, Delivery47.1 \\
\hline Lubrication & & Non lubricant(Dry) \\
\hline
\end{tabular}

\subsection{Temper Rolling Conditions}

Table 1 shows the specifications of the 4-high rolling mill and the rolling conditions. The work rolls' surfaces were dull-finished by either electric-discharged machining or shot blasting. Hereafter, these work rolls are referred to as the ED roll and the SD roll respectively. The diameters of the ED roll and SD roll are 131-133 $\mathrm{mm}$. The Ra values of these rolls are $2.1-2.3 \mu \mathrm{m}$ and $1.2-1.4 \mu \mathrm{m}$ respectively. Surface imprinting of rolled steel has been observed after $80 \mathrm{~m}$ of rolling. The peak part of the work roll surface is worn by contact with the backup roll and the rolled steel at the rolling length in a 4-high rolling mill. The diameter of the backup roll is $200 \mathrm{~mm}$, and the $\mathrm{Ra}$ is $0.25 \mu \mathrm{m}$. The hardness of the ED roll ( $83 \mathrm{Hs})$ is slightly lower than that of the SD roll $(89 \mathrm{Hs})$ and that of the backup roll $(85 \mathrm{Hs})$. The inlet and outlet tensions were adjusted to $32.4 \mathrm{MPa}$ and 47.1 $\mathrm{MPa}$ respectively, which are equivalent to those of the actual rolling mills. The standard rolling speed was $50 \mathrm{~m} / \mathrm{min}$. The strain rate of this rolling speed is equivalent to that obtained by the actual rolling mills with a work roll diameter of $550 \mathrm{~mm}$ at a rolling speed of $200 \mathrm{~m} / \mathrm{min}$. In addition, the rolling speed was set at $7.5 \mathrm{~m} / \mathrm{min}$, which is the minimum speed necessary for stable rolling, in order to evaluate the influence of the rolling speed on the surface imprinting.

\subsection{Measurement of Reduction}

Before rolling, marks were put on the surface of the

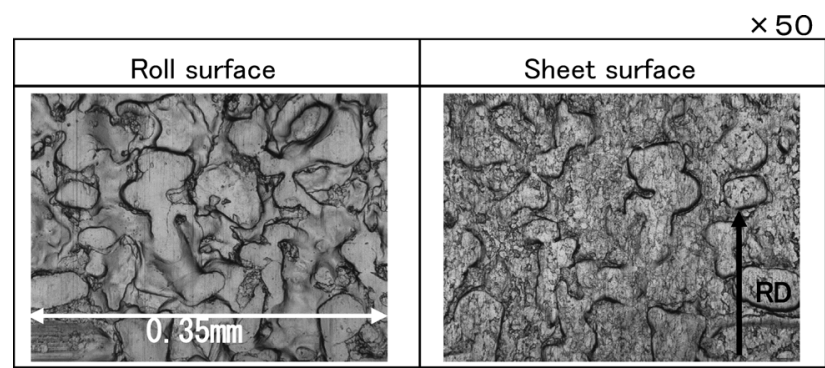

Fig. 2. Roll and sheet surfaces after temper rolling.

whole steel strip at intervals of $300 \mathrm{~mm}$. After rolling, the distances between the marks were measured. The reduction of the rolled steel sheets thickness was calculated based on the elongation rate of the distances.

\subsection{Observation of Roll and Steel Sheet Surface}

After rolling, the part on the roll surface imprints at the same position on the steel strip surface, was directly observed by a laser microscope and SEM (Fig. 2). In the microscope image (the range of which was $0.35 \times 0.35 \mathrm{~mm}$ ), the focused images were recorded by shifting the stage in the $Z$-axis direction (roughness direction), and the recorded images were converted into three-dimensional profile data. Based on the obtained data, the surface imprinting was evaluated. In particular, the Ra, the three-dimensional profile, the cross-sectional profile, the material ratio curve, and the probability density were used for this evaluation.

\subsection{Measurement of Surface Imprinting}

Surface imprinting was evaluated based on these experimental results. The imprinting ratio was obtained by the following formula:

Imprinting ratio $(\%)=(\mathrm{Ra}$ of steel sheet after rolling $-\mathrm{Ra}$ of steel sheet before rolling)/(Ra of roll after $80 \mathrm{~m}$ rolling$\mathrm{Ra}$ of steel sheet before rolling) $\times 100$

\section{Experimental Results}

\subsection{Influence of Reduction on Surface Imprinting}

The as-annealed high-carbon steel strips were conducted using the ED roll at a rolling speed of $50 \mathrm{~m} / \mathrm{min}$ and at a reduction of between $1 \%$ and $11 \%$. Figure 3 shows the relationship between the reduction and the rolling force. The rolling force increases in proportion to the reduction. Fig- 


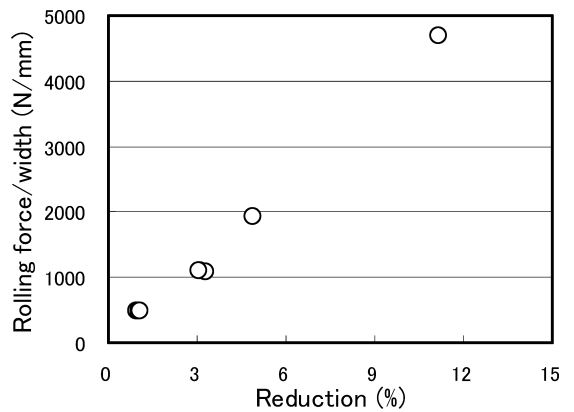

Fig. 3. The relationship between the rolling force/width and reduction (ED roll, high carbon steel sheet).

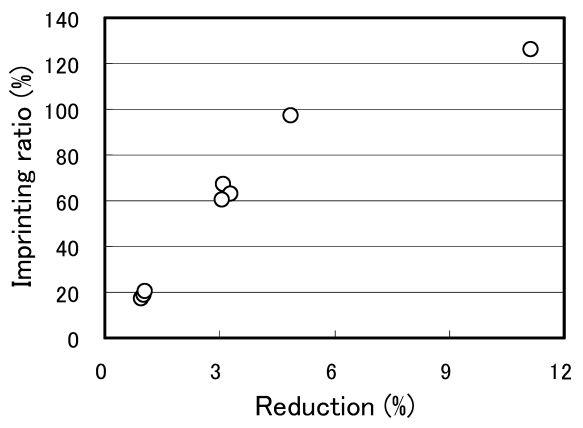

Fig. 4. The relationship between the imprinting ratio and reduction (ED roll, high carbon steel sheet).

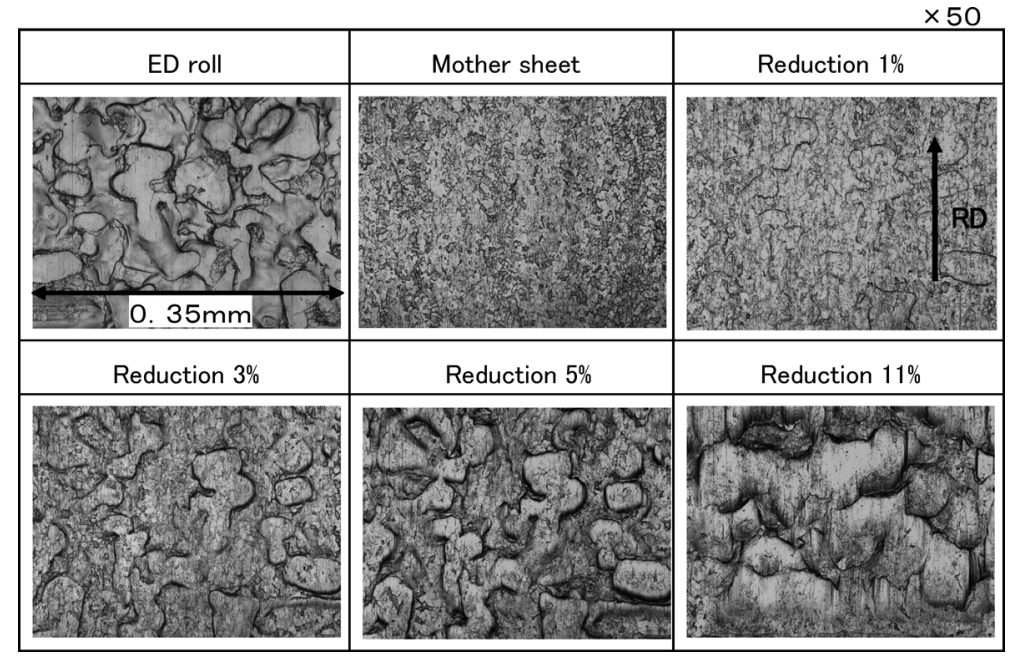

Fig. 5. Microscope images of high carbon steel sheet surfaces after temper rolling with ED roll.

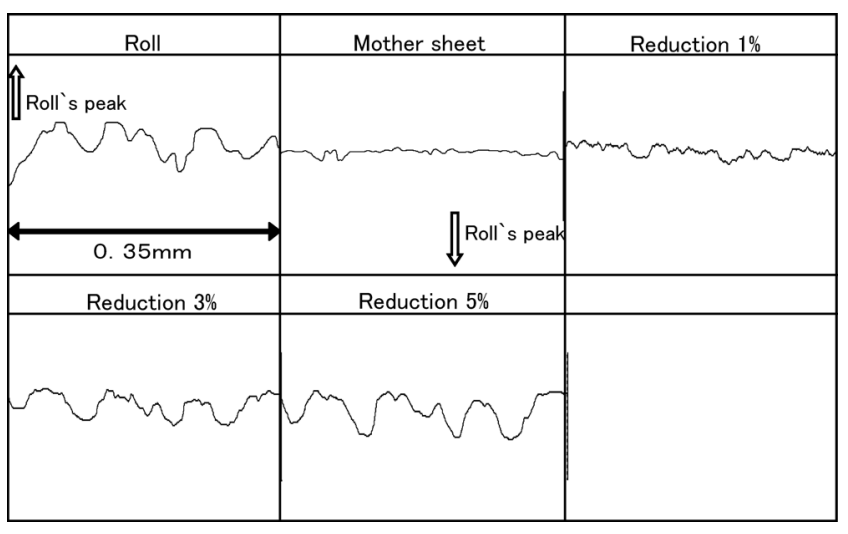

Fig. 6. Cross section profiles of high carbon steel sheet surfaces after temper rolling with ED roll.

ure 4 shows the relationship between the reduction and the imprinting ratio. The imprinting ratio increases in proportion to the reduction to a maximum of $5 \%$, and the imprinting ratio reaches $100 \%$ at a reduction of $5 \%$. When the reduction is more than $5 \%$, the imprinting ratio is not in proportion to the reduction and is more than $100 \%$. Then, the steel sheet surface after rolling was observed. Figure 5 shows the laser microscope images of the roll surface and the steel sheets surface before and after rolling at the reductions of between $1 \%$ and $11 \%$. At the $1 \%$ reduction, a part of the roll surface texture is imprinted on the steel sheet surface. When the reductions are $3 \%$ and $5 \%$, the detailed texture of the roll surface is imprinted on the steel sheet

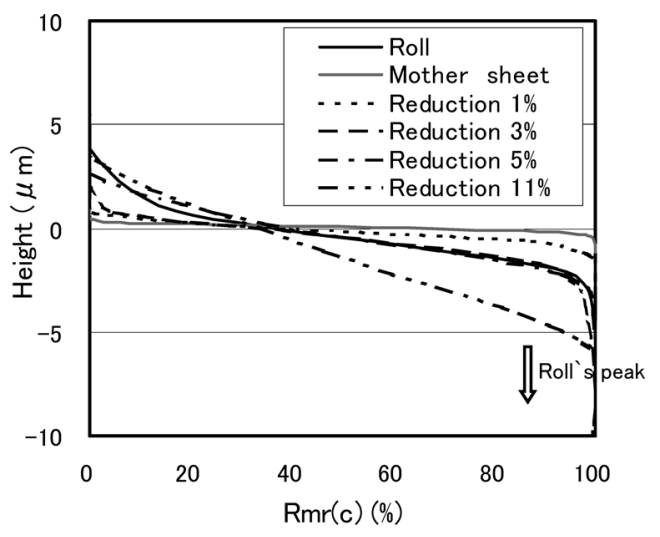

Fig. 7. Material ratio curves of high carbon steel sheet surfaces with ED roll.

surface. At the reduction of $11 \%$, galling occurs, and consequently, the surface texture of the steel sheet entirely differs from that of the roll. Figure 6 shows the cross-sectional profiles of the rolls and rolled steel sheets. The peak part of the rolls surface texture is directly imprinted on the steel sheet surface to form the valley part of the steel sheets at the reduction of $1 \%$. At the reductions of $3 \%$ and $5 \%$, the peak part of the roll surface is deeply imprinted on the steel sheet surface to form the valley part of the steel sheet. Figure 7 shows the material ratio curves of the rolls and rolled steel sheets obtained using the three-dimensional profile data. In the figure, the positive and negative sides of the vertical axis express the peak and valley parts of the 


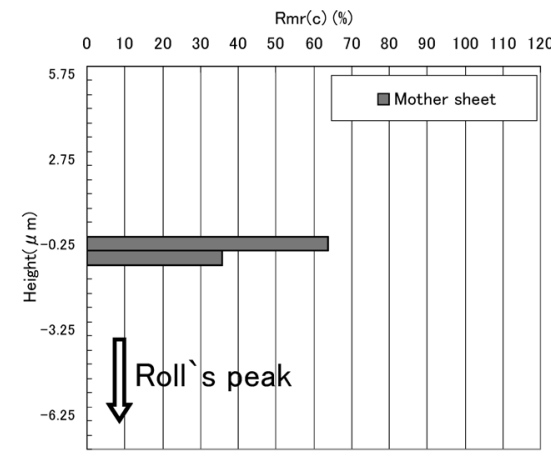

(a) Mother sheet

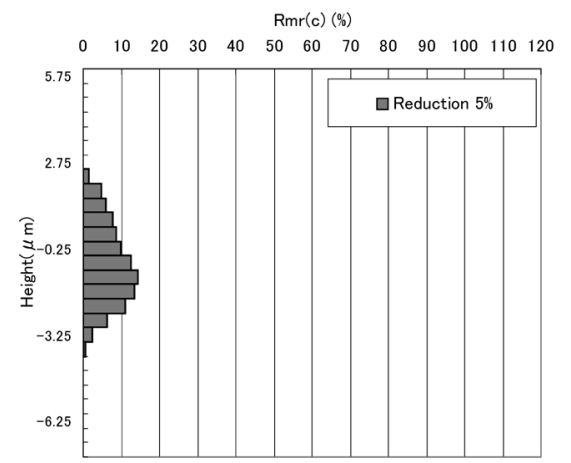

(d) Sheet(reduction 5\%)

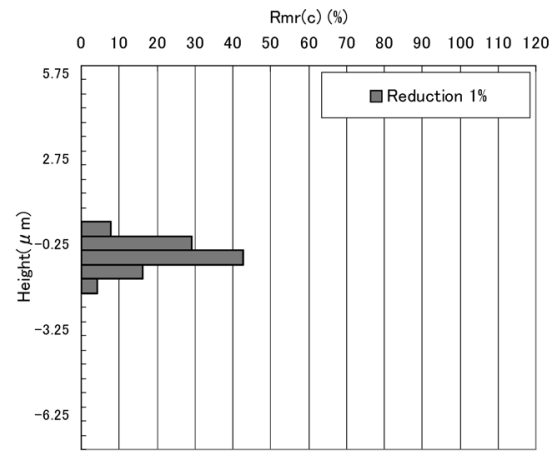

(b) Sheet(reduction 1\%)

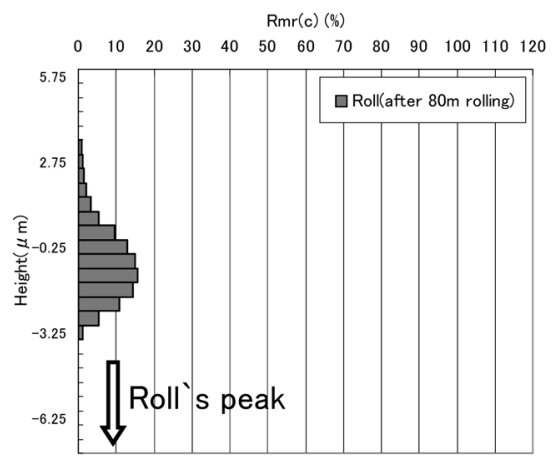

(e) ED roll

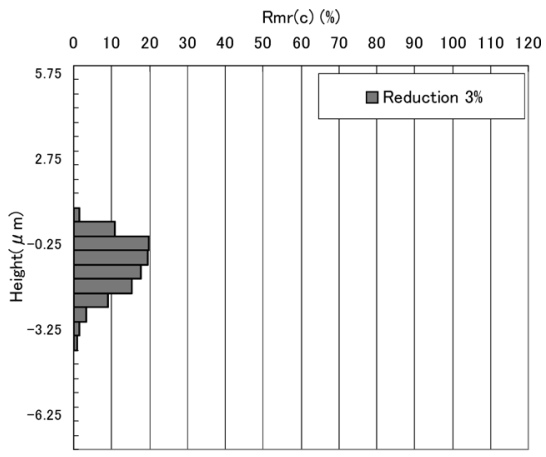

(c) Sheet(reduction 3\%)

Fig. 8. Probability densities of sheet surfaces with ED roll.

steel sheet respectively. The positive and negative sides of ordinate for the roll are reversed in order to compare the surface profile of the steel sheets with that of the roll directly, because the peak part of the roll corresponds to the negative side of the steel sheets. The shape of the valley part of the steel sheet's curve is close to that of the roll's curve at the reduction of $1 \%$. At reductions of $3 \%$ and $5 \%$, the shapes of the valley part on the steel sheet's curve are almost similar to those of the roll's curve. At the reduction of $11 \%$, the shape of the valley part of the steel sheet's curve is entirely different from that of the roll's curve. On the other hand, the shape of the peak part of the steel sheet is closer to that of the roll's curve as the reduction increases. However, the shape of the peak part of the steel sheet's curve is not similar to that of the roll's curve at any reduction. Figure 8 shows the probability densities of the rolls and rolled steel sheets obtained by the material ratio curves. The positive and negative sides of the vertical axis express the peak and valley parts of the steel sheet respectively. At the reduction of $1 \%$, the probability densities of the steel sheet after rolling is slightly biased toward both the peak and valley parts of the steel sheet. At the reduction of $3 \%$, the probability density of the steel sheets are greatly biased toward the peak part of the steel sheet and are similar to the peak part of the roll. Furthermore, at the reduction of $5 \%$, there is a great bias toward the peak and valley parts of the steel sheet.

\subsection{Influence of Rolling Speed}

Temper rolling experiments were performed at rolling speeds of $7.5 \mathrm{~m} / \mathrm{min}$ and $50 \mathrm{~m} / \mathrm{min}$, in order to evaluate the influence of the rolling speed on surface imprinting. The

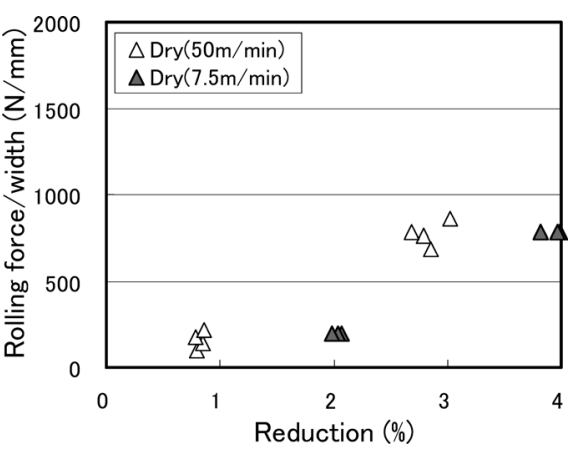

Fig. 9. Comparison of rolling speed on rolling force/width (low carbon steel sheet).

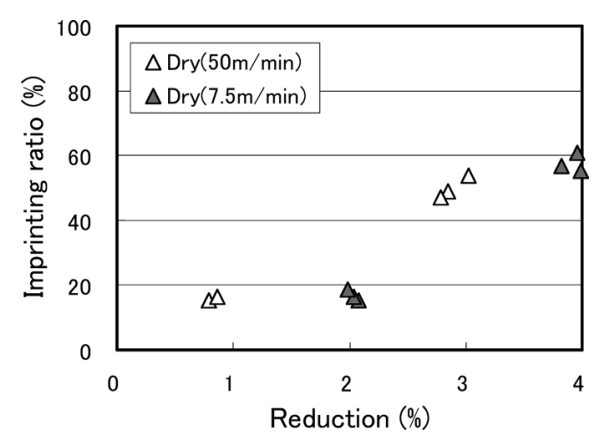

Fig. 10. Comparison of rolling speed on imprinting ratio (low carbon steel sheet).

SD roll and the low-carbon steel strip are employed in these experiment. Figure 9 shows the relationship between the reduction and the rolling force. The rolling force increases in the higher rolling speed at the same reduction. Figure 10 shows the relationship between the reduction and the im- 

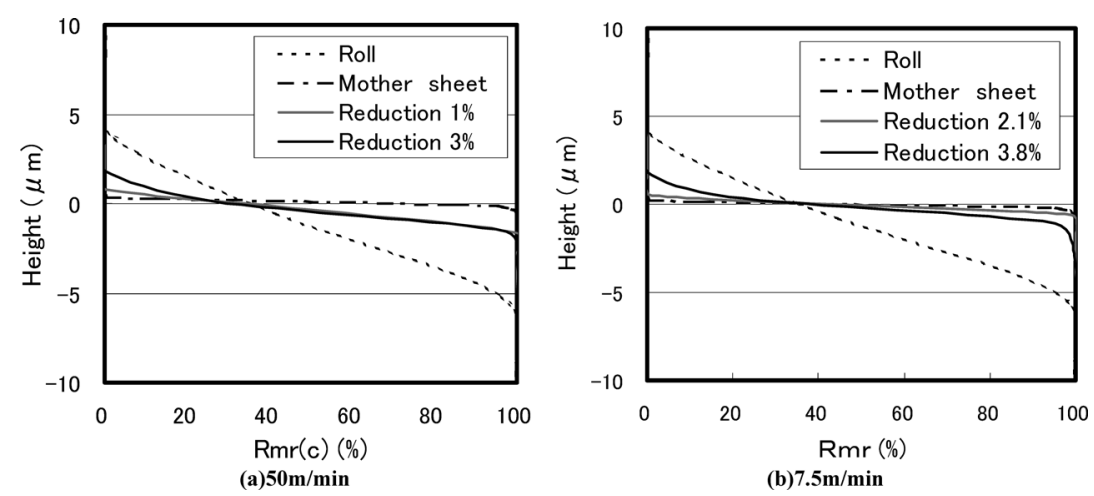

Fig. 11. Material ratio curves of low carbon steel sheet surfaces at low speed with SD roll.

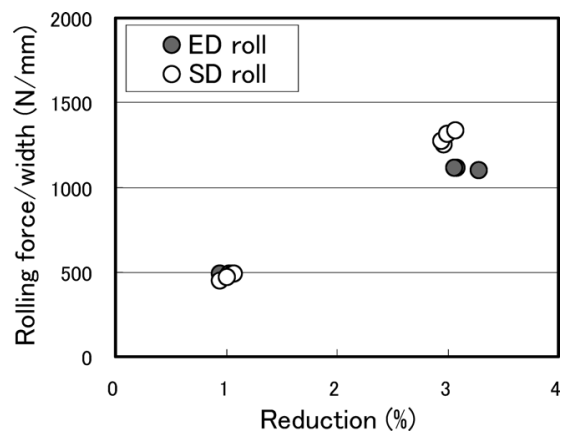

Fig. 12. Comparison of roll dull method on rolling force/width (high carbon steel sheet)

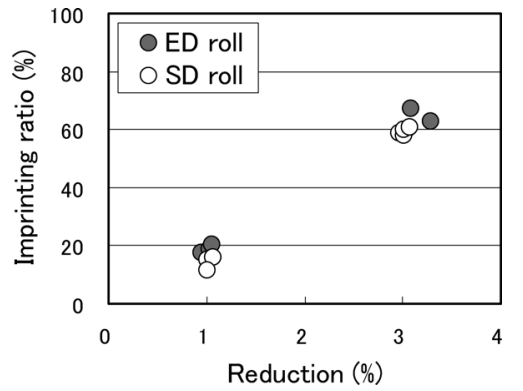

Fig. 13. Comparison of roll dull method on imprinting ratio (high carbon steel sheet).

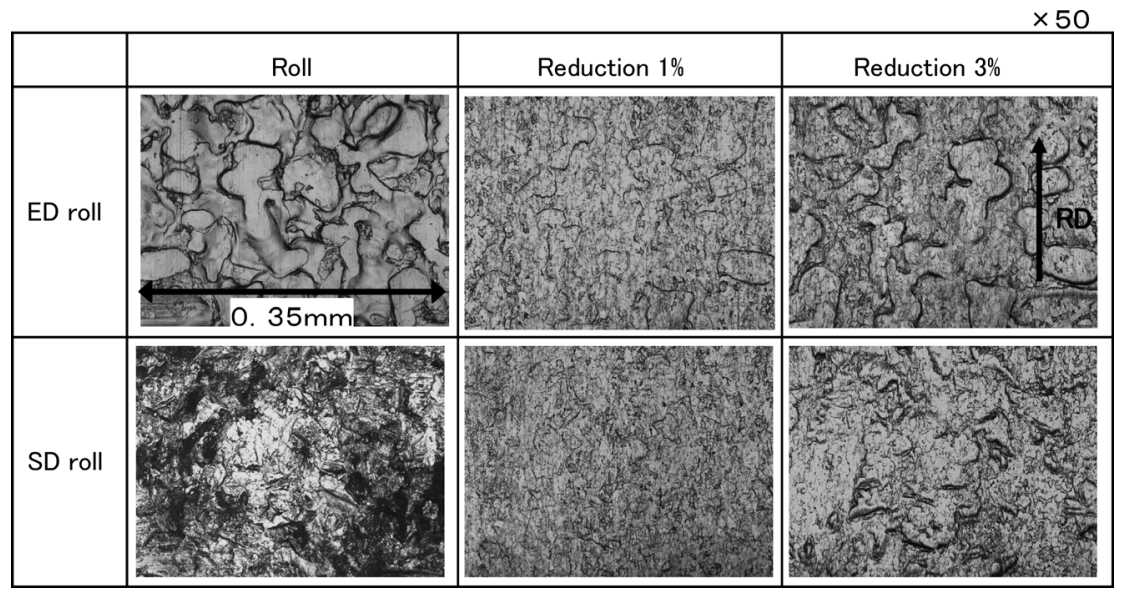

Fig. 14. Microscope images of high carbon steel sheet surfaces after temper rolling with rolls.

printing ratio. The imprinting ratio in high-speed rolling is higher than that in low-speed rolling. Figure 11 shows the material ratio curves. The shape of the valley part of the steel sheet's curve is closer to that of the roll's curve at the rolling speed of $50 \mathrm{~m} / \mathrm{min}$ than that at $7.5 \mathrm{~m} / \mathrm{min}$.

\subsection{Influence of Roll Surface Texture on Surface Im- printing}

Using the ED roll and the SD roll, the high-carbon steel strips were rolled at the reductions of $1 \%$ and $3 \%$. Figure 12 shows the relationship between the reduction and the rolling force. The rolling force increases simultaneously with increase in the reduction of either the ED roll or the $\mathrm{SD}$ roll. At the reduction of $1 \%$, no difference is observed in the rolling force between the ED roll and the SD roll. At the reduction of $3 \%$, the rolling force of the ED roll is lower than that of the SD roll. Figure 13 shows the rela- tionship between the reduction and the imprinting ratio. The imprinting ratio of the ED roll is slightly higher than that of the SD roll. Figure 14 shows the laser microscope images of the steel sheet surfaces after rolling at the reductions of $1 \%$ and $3 \%$. A part of the surface texture of either roll is imprinted on the steel sheet surface at the reduction of $1 \%$. The surface imprinting phenomenon is clearer at the reduction of $3 \%$ than that of $1 \%$. At both reductions, the surface texture of the ED roll is more clearly imprinted on the steel sheet surface than that of the SD roll. This fact can be confirmed by the SEM images shown in Figs. 15 and $\mathbf{1 6}$ shows the cross-sectional profiles of the surface roughness. The peak part of the roll surface is directly imprinted on the steel sheet surface to form the valley part of the steel sheet at the reduction of $1 \%$. At the reduction of $3 \%$, the peak part of the roll surface is deeply imprinted on the steel sheet surface to form the valley part of the steel sheet. Figure 17 
shows the material ratio curves. The shape of the valley part of the steel sheet's curve is close to that of the roll's curve at the rolling reduction of $1 \%$. At the reduction of

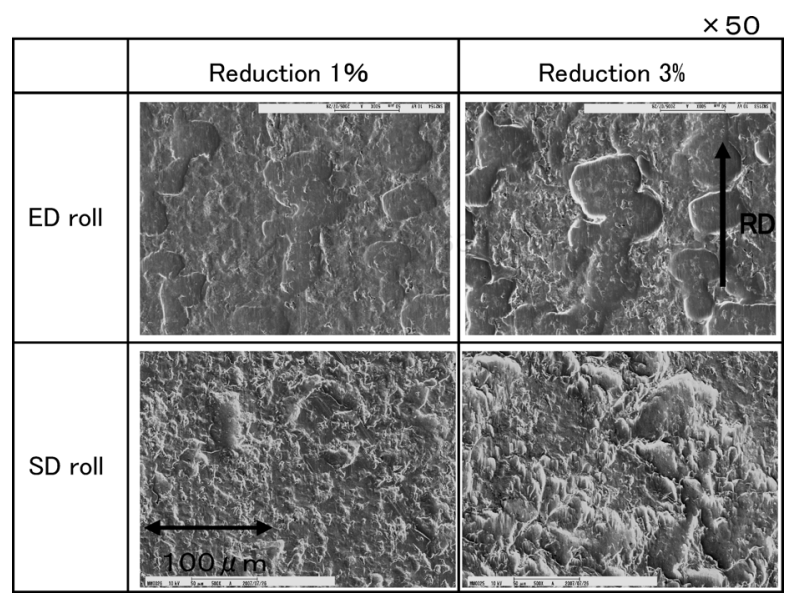

Fig. 15. SEM images of high carbon steel sheet surfaces after temper rolling.
$3 \%$, the shape of the valley part on the steel sheet's curve is almost similar to that of the roll's curve when the ED roll is used. On the contrary, the shape of the valley part on the steel sheet's curve is not closer to that of the roll's curve although the reduction increased to $3 \%$ when the SD roll is used. The shape of the peak part of the steel sheet's curve is also closer to that of the roll's curve when the ED roll is used than when the SD roll is used.

\subsection{Comparison of Surface Imprinting of High- and Low-carbon Steel}

Figure 18 shows the relationship between the reduction and the rolling force when high- and low-carbon steel strips were rolled using the ED roll. The rolling force increases as the reduction increases in both steel. Figure 19 shows the relationship between the reduction and the imprinting ratio. The imprinting ratio of the high-carbon steel sheet is slightly higher than that of the low-carbon steel sheet at the reduction of $1 \%$ and $3 \%$ respectively. The material ratio curves shown in Fig. 20 indicate that the shape of the valley

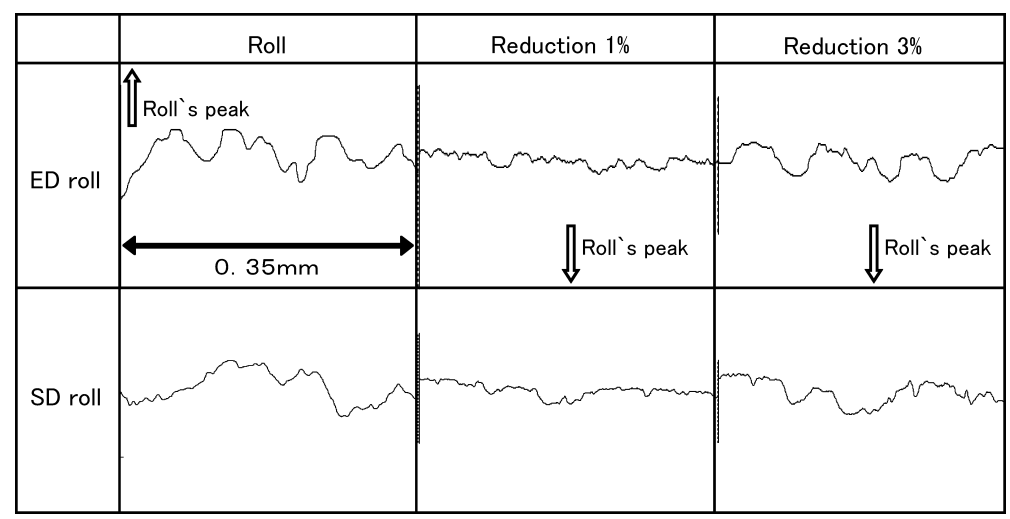

Fig. 16. Cross section profiles of high carbon steel sheet surfaces after temper rolling with rolls.
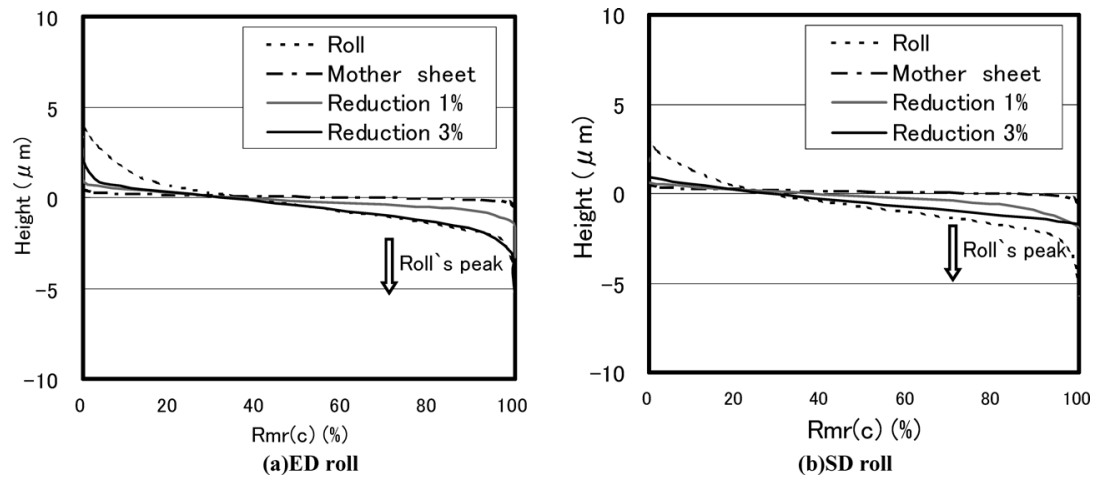

Fig. 17. Material ratio curves of high carbon steel sheet surfaces with rolls.

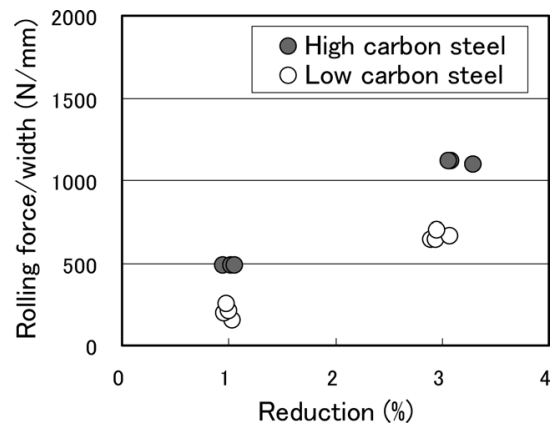

Fig. 18. Comparison of roll dull method on rolling force/width (low carbon steel sheet).

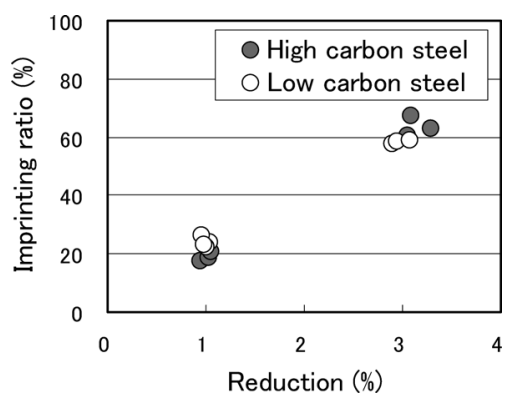

Fig. 19. Comparison of roll dull method on imprinting ratio (low carbon steel sheet). 

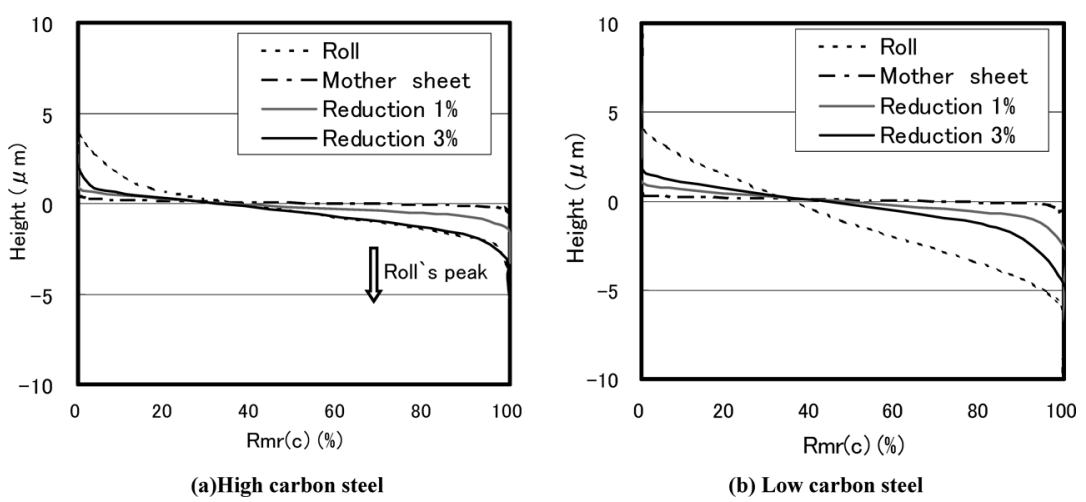

Fig. 20. Material ratio curves of low carbon steel sheet surfaces with rolls.

part on the steel sheet's curve is closer to that of the roll's curve in the high-carbon steel sheet than in the low-carbon steel sheet.

\section{Discussion}

\subsection{Influence of Rolling Reduction}

Based on the material ratio curves shown in Fig. 7, the surface imprinting from the roll on the steel sheet is considered as follows: (1) the peak part of the roll surface is pressed on the steel sheet surface and the valley part forms on the steel sheet surface; namely, the shape of the valley part on the steel sheet is similar to that of the peak part on the roll surface; (2) when the reduction increases, the deeper valley part forms; (3) simultaneously, the valley part of the steel sheets is the plastic flows to the valley part on the roll to form the peak part on the steel sheet; and (4) when the reduction is higher, a larger amount of steel's plastic flows shifts to form higher peak part of the steel sheet. However, when the reduction becomes as high as $11 \%$, the shape of the steel sheet surface becomes entirely different from that of the roll surface. Moreover, the imprinting ratio exceeds the roll surface roughness $(100 \%)$. At this time, since a deformation due to shearing occurs and a galling part is also observed, no surface imprinting proceeds.

\subsection{Influence of Rolling Speed}

The imprinting ratio increases at the higher rolling speed. As shown in Fig. 11, the shape of the valley part of the steel sheet is closer to that of the roll's curve at the rolling speed of $50 \mathrm{~m} / \mathrm{min}$ than that at $7.5 \mathrm{~m} / \mathrm{min}$. Therefore, it is confirmed that the peak part of the roll surface is more easily pressed on the steel sheet to form the valley part at the higher rolling speed.

\subsection{Influence of Roll Surface Texture}

The imprinting ratio obtained by using the ED roll is slightly higher than that obtained by using SD roll. Therefore, the roll surface texture is considered to affect surface imprinting. Based on the material ratio curves shown in Fig. 15, it is confirmed that the peak part of the roll surface is more easily imprinted on the steel sheet to form the valley part when the ED roll is used than when the SD roll is used.

\section{Conclusions}

The effects of roll surface texture on surface imprinting have been evaluated. Temper rolling experiments for asannealed carbon steel strips are performed using a 4-high rolling mill under dry rolling conditions. Electric-discharged dull roll (ED roll) and shot dull roll (SD roll) were employed as work rolls. The following results are obtained:

(1) In temper rolling, the peak part of the roll surface texture can be directly imprinted on the steel sheet surface to form the valley part. Simultaneously, the steel's plastic flows from the valley part to the place corresponding to the valley part on the roll to form the peak part on the steel sheet. When the reduction increases, the valley and peak parts become deeper and higher respectively. When the reduction becomes as high as $11 \%$, galling occurs on the steel sheet surface, and the shape of the steel sheet surface becomes entirely different from that of the roll surface.

(2) The imprinting ratio in high-speed rolling is higher than that in low-speed rolling.

(3) The ED roll results in a better surface imprinting than the SD roll.

(4) The material ratio curve and the probability density are available to evaluate surface roughness imprinting in detail.

(5) The effect of water-soluble lubricant condition on surface imprinting is evaluated in another paper.

\section{REFERENCES}

1) I. Aoki: J. Jpn. Soc. Technol. Plast., 20 (1979), 1121.

2) Y. Kimura, M. Ueno and Y. Sodani: CAMP-ISIJ, 18 (2005), 1214.

3) H. Hasimoto: J. Jpn. Soc. Technol. Plast., 20 (1979), 1121.

4) M. Yamasita: J. Jpn. Soc. Technol. Plast., 36 (1995), 1116.

5) G. Kawaguchi, S. Muto, A. Torao and H. Uchida: CAMP-ISIJ, 9 (1996), 1341.

6) A. Torao and I. Yarita: The collected papers of the 49th Japanese Joint Conf. for the Technology of Plasticity, (1998), 255.

7) N. Nagase, S. Shido and I. Yarita: CAMP-ISIJ, 17 (2004), 1015.

8) N. Nagase, S. Shido and I. Yarita: CAMP-ISIJ, 18 (2005), 425.

9) N. Nagase, S. Shido and I. Yarita: CAMP-ISIJ, 18 (2005), 1217.

10) N. Nagase, S. Shido and I. Yarita: The collected papers of the 36th Spring Conf. for the Japanese Society for Technology of Plasticity, (2005), 223.

11) N. Nagase, S. Shido and I. Yarita: The draft papers of the Japanese Society of Tribologists Fall Meeting 2005, (2005), 283.

12) N. Nagase, S. Shido and I. Yarita: CAMP-ISIJ, 19 (2006), 404

13) N. Nagase, S. Shido and I. Yarita: CAMP-ISIJ, 19 (2006), 985

14) N. Nagase, S. Shido and I. Yarita: CAMP-ISIJ, 20 (2007), 63. 